\title{
Simplified Analysis of Pure Conical Water Vessels under Hydrostatic Loading
}

\author{
Maryam Ayman Seleemah*¹, Ahmed Elansary ${ }^{2}$ and Saher Elkhoreby ${ }^{1}$ \\ ${ }^{1}$ Structural Engineering Department, Faculty of Engineering, Tanta University, Tanta, Egypt \\ 2 Structural Engineering Department, Faculty of Engineering, Cairo University, Giza, Egypt. \\ Email: maryam.seleemah@f-eng.tanta.edu.eg
}

\begin{abstract}
Liquid storage structures represent an important component of modern infrastructure. They can take variety of shapes of which the conical shape is one of the most common configurations. Both architects and structural engineers because of their appealing look and structural efficiency in addition to their large capacities with relatively small footprint area prefer conical tanks. The state of stresses in these tanks is rather complicated and needs powerful computational tools. However, in the preliminary design phase, it is important to have a simplified analysis method for selection of economic design parameters including tank height, inclination angle, and footprint radius needed to achieve the desired tank capacity. It is also of importance that the structural engineer has an insight and understanding of the effect of these various parameters on the resulting internal forces acting on the tank. This paper presents a simplified analysis of conical tanks under hydrostatic loading based on the application of the membrane theory. The equations governing the behavior of these structures are first derived. Then, they are applied on several vessels of practical dimensions and the resulting of stresses are presented to give a deeper understanding of the resulting internal actions. Moreover, a simple guide to achieve efficient structural preliminary design parameters for a wide range of tank capacities is introduced.
\end{abstract}

Keywords- Conical tanks, Hydrostatic loading, Membrane theory, Surface of revolution, Meridional and circumferential forces.

\section{INTRODUCTION}

Vessels with conical shapes are commonly used as liquid containments around the world because they have a limited footprint and a large storage capacity. Generally, architects prefer the conical configuration over rectangular or cylindrical ones because they are more aesthetically appealing. Structural engineers also would prefer this system compared to the cylindrical shape to avoid the need of significantly thick cantilever slab in cylindrical tanks. However, several serious conical tanks' failures occurred in the past causing significant economic losses. These failures motivated many researchers to study the behavior and design of these structures under both hydrostatic and seismic loadings. For example, in Belgium, 1972, a steel water tower with a capacity of more than 1000 tons collapsed while the tank was being filled for the first time and before the water reached the overflow level, as reported by Vandepitte [1]. Another collapse of an elevated conical water tower occurred in Fredericton, Canada, in 1990 and was reported by Korol [2]. The investigations of those steel conical tanks revealed that the collapse occurred due to buckling under hydrostatic pressure.

Conical vessels generally have two common shapes: pure and combined. When vessel consists entirely of a truncated conical shape, it is referred to as "Pure Conical Tank". On the other hand, when the containment vessel has a truncated conical shape with a superimposed cylindrical cap, this vessel configuration is referred to as "Combined Conical Tank". Moreover, these tanks can be ground supported or elevated on a supporting shaft, as shown in Fig.1.

Numerous experimental investigations focusing on the structural behavior of conical vessels under hydrostatic loadings have been conducted. Vandepitte et al. [3] investigated the stability of hydrostatically loaded conical shells supported only along the lower edge. They conducted an extensive experimental test program covering 768 models made of different materials (mylar, brass, aluminum and steel) with varying thicknesses, inclination angels and boundary conditions. All models were filled with water until they collapsed and the water heights at which buckling occurred were recorded.

Other research studies were conducted numerically El Damatty et al. [4] studied the stability of steel liquid-filled conical tanks under hydrostatic loading taking into account the effects of geometric imperfections and residual stresses. A finite-element formulation based on a consistent shell element, developed by Koziey and Mirza [5] and then extended by El Damatty et al. [6] to include both geometric and material nonlinearities, was used. Elastic stability analyses of conical shells with different geometric imperfection patterns were undertaken. The results of this study indicated that the presence of axisymmetric imperfections leads to the lowest limit load for the structure. The results also revealed that yielding typically precedes elastic buckling for tanks having practical dimensions.

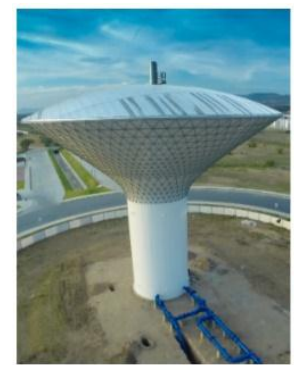

(a)

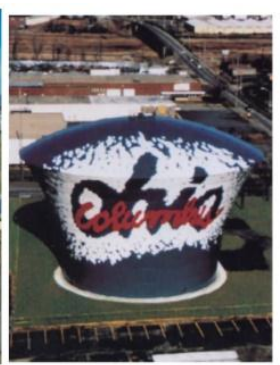

(b)

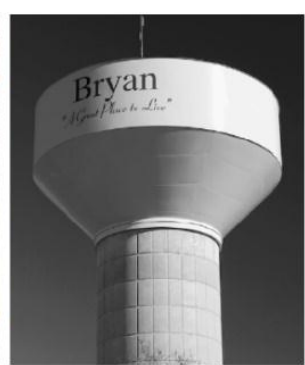

(c)
Figure 1. Geometry variations of conical tanks

(a) Photograph of an elevated pure conical tank, (b) Photograph of a ground-supported pure conical tank, and (c) Photograph of an elevated combined conical tank.

It is worth mentioning that this study was followed by a valuable discussion between Vandepitte and El Damatty 
considering elastic and inelastic buckling and effect of residual stresses due to welding [7]. Based on their discussion, it was concluded that yielding might have happened during the buckling process of the cones tested by Vandepitte et al. [4].

El Damatty et al. [8] developed a procedure to determine the critical imperfection shape in conical tanks by assuming an imperfect shape in the form of Fourier series with equal coefficients associated with all harmonics. In the same study, stability analyses were conducted on the small-scale tanks tested by Vandepitte et al. [3]. The buckling wavelength and the critical water heights obtained from these analyses were shown to agree with the experimental results. The study also confirmed that axisymmetric imperfections are the most critical for conical tanks and that yielding typically precedes buckling in those hydrostatically-loaded structures. Similar conclusion was obtained by Lagae et al. [9] who constructed numerical models for a series of imperfect conical tanks and explained how the imperfections can cause large circumferential tensile stresses eventually leading to plastic collapse of the tank.

Tekleab [10] studied the stability of cylindrical and conical thin-walled tanks under hydrostatic loading. The axisymmetric elastic-plastic buckling phenomena, buckling modes and strengths of meridionally compressed and internally pressurized cylindrical and conical shells were investigated. Simplified expressions were obtained for the prediction of axisymmetric elastic-plastic buckling strength of general thinwalled cylindrical and conical shells.

The consistent shell element by Kozeiy and Mirza [6] was utilized by Azabi et al. [11] to study the linear behavior of reinforced concrete conical tanks under hydrostatic pressure. The results of this Finite Element Model (FEM) and an approximate method based on using equations from the Portland Cement Association, (PCA) design aids [12] combined with the equivalent cylindrical approach by the American Water Works Association (AWWA) [13], were compared. It was concluded that the approximate approach can be used to design tank walls to resist only ring tension and meridional moment. However, the equivalent cylindrical approach does not account for the meridional compression existing in conical tanks. This may lead to an inadequate design resulting from following the approximate approach.

Elansary et al. [14] and Elansary and El Damatty [15] extended Azabi et al. [11]'s FEM to account for shrinkage and creep as well as the nonlinear behavior of concrete. The nonlinearity of concrete was considered by including a concrete constitutive model previously developed by Pietruszczak et al. [16] and Jaing [17]. The developed nonlinear FEM was used to study the behavior of hydrostatically loaded concrete conical tanks with a wide range of practical dimensions. It was reported that the maximum deflection of the tank's wall occurs at the middle one-third of the tank height while the maximum hoop stress occurs at $1 / 5-1 / 6$ of the tank's height. It was also reported that the maximum meridional stress in the concrete wall and reinforcing bars occur within the bottom $10 \%$ region of the tank's vessel.

Conical and cylindrical concrete tanks were studied by Bruder [18] by comparing two different analysis tools; (i)
Circular Concrete Tanks (CCT) Without Pre-stressing by PCA [12] and (ii) three-dimensional FEM using a commercial software program. Comparisons between internal forces obtained from the two tools were made to investigate the range of internal force discrepancies. Finally, recommendations regarding the analysis of these tanks were provided. It was recommended that an FEM should better be employed if the geometry, loads, and boundary conditions of the tank are outside the parameters outlined by CCT. Otherwise, the internal forces obtained from CCT would lead to an inadequate design. However, they pointed out that the use of FEM needs prior modeling experience and context for the analysis output or else misleading results might not be recognized.

Composite steel-concrete conical tanks under hydrostatic pressure were investigated by Elansary and El Damatty [19]. A Finite Element Model for Composite tanks (CFEM), which accounts for both geometric and material nonlinearities, was developed. The material nonlinearity was considered by including nonlinear models for steel, concrete, and the connecting studs. In the CFEM, both the concrete and steel walls were modelled using the consistent shell element, previously developed by Koziey and Mirza [5], while the connecting studs between the two walls were modelled using a contact element based on a smearing approach. This contact element was previously developed by Siddique and El Damatty [20] to model the interface between steel plates and Glass Fiber Reinforced Polymer (GFRP) plates. An Equivalent Section Method (ESM) for the analysis of composite tanks, which is based on using an equivalent single wall, was introduced. It was concluded that the values of the load capacity, displacements, forces, and stresses estimated by the ESM in both the concrete wall and the steel shell, were significantly less than those predicted by the CFEM.

The current paper presents a simplified technique to analyze conical tanks under hydrostatic loading based on the application of the membrane theory. Such analysis might help the design engineers to obtain an insight about the internal forces acting on these structures in the hoop and meridional directions. For this, the simplified equations were applied on several vessels with practical dimensions and the resulting state of stresses were presented. Moreover, a simple guide to achieve efficient structural preliminary design parameters for a wide range of tank capacities was introduced.

\section{Simplified ANALYSIS PROCEDURE}

The internal actions in thin shells shaped in the form of surfaces of revolution are quite complicated. Generally, each side of an element cut out of the thin shell is subjected to various types of internal actions. These are normal force, a tangential in plane shearing force, a transverse out of plane shearing force, bending moment and twisting moment. Numerical procedures such as finite element method can be used to obtain the solution involving these internal actions. On the other hand, a simplified approach can be adopted to get an insight into the general internal forces acting on these tanks that is sufficiently accurate for preliminary design purposes. 
This approach is generally referred to as the membrane theory. In this theory, the transverse shear, the bending moment, and the twisting moment are neglected. Therefore, only the normal force and tangential shearing force are considered. However, for axisymmetrically loaded shell of revolution, it can be proved that the tangential shearing force is equal to zero and only the normal forces acting on the sides of the element remain. Usually, these components are referred to as the meridional (axial) forces and the circumferential (ring or hoop) forces. The general equations that govern these forces are as following. (refer to Fig. 2) [21]:

$$
\begin{aligned}
& \frac{N_{\emptyset}}{r_{1}}+\frac{N_{\theta}}{r_{2}}=p_{r} \\
& r \sin \emptyset N_{\varnothing}=\int r_{1} r_{2}\left(p_{r} \cos \emptyset-p_{\emptyset} \sin \emptyset\right) \sin \emptyset d \emptyset
\end{aligned}
$$

Where:

$\mathrm{N}_{\phi}, \mathrm{N}_{\Theta}$ are the internal forces per unit length acting in the meridional and circumferential directions, respectively. $\phi$ is the angle between the normal to the surface of the shell at all points of a parallel circle and the axis of the shell, i.e., it can define the parallel circle.

$r$ is the radius of the parallel circle.

$\mathrm{r}_{1}, \mathrm{r}_{2}$ are the principal radii of curvature, as shown in Fig. 2

$\mathrm{P}_{\mathrm{r}}, \mathrm{P}_{\phi}$ are the two components of axisymmetric external surface load per unit area in the directions normal and tangent to the shell, respectively. (Since the load is axisymmetric, these components are independent of the coordinate $\Theta$ )

In case of conical shells, the angle $\phi$ is constant and cannot serve as coordinate. Instead, a parallel circle is defined by the distance S from the apex (see Fig. 3). Replacing the subscript $\phi$ by $S$ and using the following relations, the general equations of axisymmetrically loaded shells of revolution (1) and (2) turns into equations (3) and (4) for conical shells. It is noticed that in the case of conical shells $\mathrm{N}_{\Theta}$ and $\mathrm{N}_{\mathrm{S}}$ are independent.

$$
\begin{aligned}
& r_{1} d \emptyset=d s \quad r_{1} \rightarrow \infty \quad r_{2}=\frac{S}{\tan \varnothing} \quad r=S \cos \emptyset \\
& N_{\theta}=\frac{S P_{r}}{\tan \varnothing} \\
& N_{S}=\frac{1}{S \sin \varnothing} \int S\left(p_{r} \cos \emptyset-p_{S} \sin \emptyset\right) d s
\end{aligned}
$$

For the case of conical tanks, neglecting the self-weight of the tank and taking into consideration the pressure of the contained liquid the following expressions can be obtained.

$$
\begin{aligned}
& N_{\theta}=\frac{\gamma H S}{\tan \emptyset}-\gamma S^{2} \cos \emptyset \\
& N_{S}=\frac{\gamma \cos \emptyset}{S}\left[\frac{H\left(S^{2}-S_{0}^{2}\right)}{2 \sin \varnothing}-\frac{S^{3}-S_{0}^{3}}{3}\right]
\end{aligned}
$$

Where:

$\gamma$ is the specific weight of the contained liquid.

$\mathrm{H}$ is the height measured from the apex to the liquid level. (see Fig. 3)

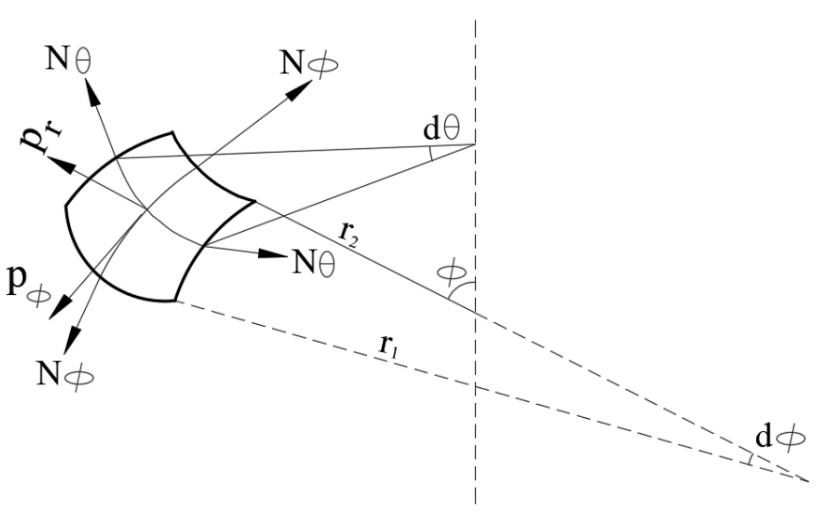

Figure 2. Meridional and circumferential forces acting on an axisymmetrically shell of revolution

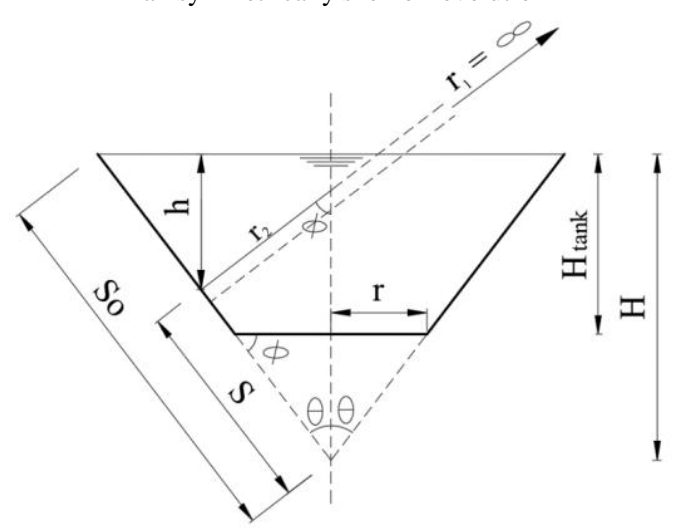

Figure 3. Dimensions of liquid filled conical tank.

$\mathrm{S}_{0}$ is the distance from the apex to the liquid level along the meridional direction, as shown in Fig. 3.

\section{ANALYSIS RESULTS}

To get an insight into the behavior of water filled conical tanks, several tanks having practical dimensions were analyzed utilizing the previously obtained equations (5) and (6). Different tank parameters were taken into consideration. These include tank inclination angles, footprint radii and heights. (See Table 1) The results of these cases are presented in the following subsections.

Table 1. Parameters of the analyzed cases

\begin{tabular}{c|c|c|c}
\hline Parameter & $\begin{array}{c}\text { Inclination } \\
\text { Angle }\end{array}$ & $\begin{array}{c}\text { Footprint } \\
\text { Radius (m) }\end{array}$ & Height (m) \\
\hline & $0^{0}$ & & \\
Effect of & $30^{0}$ & & 7 to 10 \\
Inclination Angle & $40^{0}$ & 4 & \\
& $45^{0}$ & & \\
& $50^{0}$ & & 9 \\
Effect of & $60^{0}$ & 3 & 7 \\
Footprint Radius & $45^{0}$ & 4 & 8 \\
& & 6 & 10 \\
\hline
\end{tabular}




\section{A. Effect of Inclination Angle}

The effect of various inclination angles on the resulting internal actions, for tanks having a bottom radius of $4 \mathrm{~m}$ and a height of $9 \mathrm{~m}$, is shown in Fig. 4. An inclination angle of $\Theta=$ zero represents the special case of cylindrical tank. In this case no meridional forces occur while the hoop forces follow a linear distribution resulting from increased liquid pressure starting from zero at the top to its maximum at the bottom. By increasing the inclination angle, it is observed that both the hoop and the meridional forces increase and follow a nonlinear distribution. The maximum value of the hoop forces occurs at the lower one-third of the tank height. The level of the maximum hoop force is observed to increase with the increase of the inclination angle. On the other hand, the maximum meridional forces occur at the bottom rim of the tank.

The maximum internal actions in tanks with different inclination angles are presented in Fig. 5. A mild increase of the resulting internal forces occurs up to inclination angle of $40^{0}$ after which the forces seem to rapidly increase with the increase of the inclination angle. A more pronounced increase in the meridional forces is observed.

\section{B. Effect of Tank Footprint Radius}

Conical tanks of bottom radii ranging from 3 to $6 \mathrm{~m}$ with a height of $9 \mathrm{~m}$ and an inclination angle of $45^{\circ}$ were analyzed and the resulting internal forces are shown in Figs. 6 and 7. By increasing the bottom radius, it is observed that the hoop forces increase. Moreover, the height at which the maximum

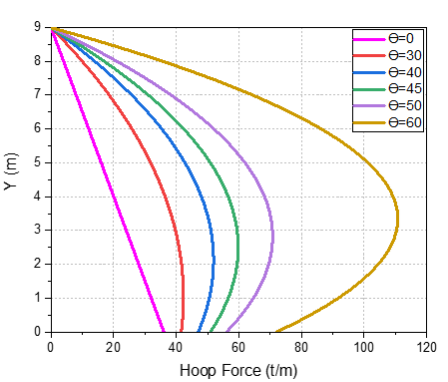

(a)

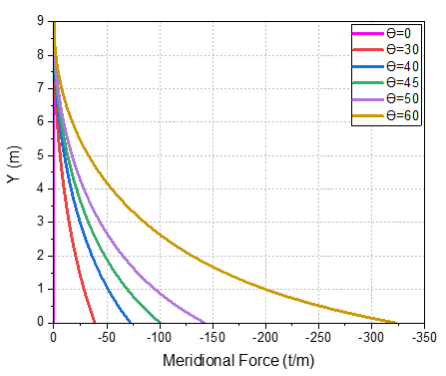

(b)
Figure 4. Distribution of internal actions for different inclination angles. ( $\mathrm{r}=4 \mathrm{~m}$ and $\mathrm{H}_{\mathrm{tank}}=9 \mathrm{~m}$ )

(a) Hoop forces, and (b) Meridional forces.

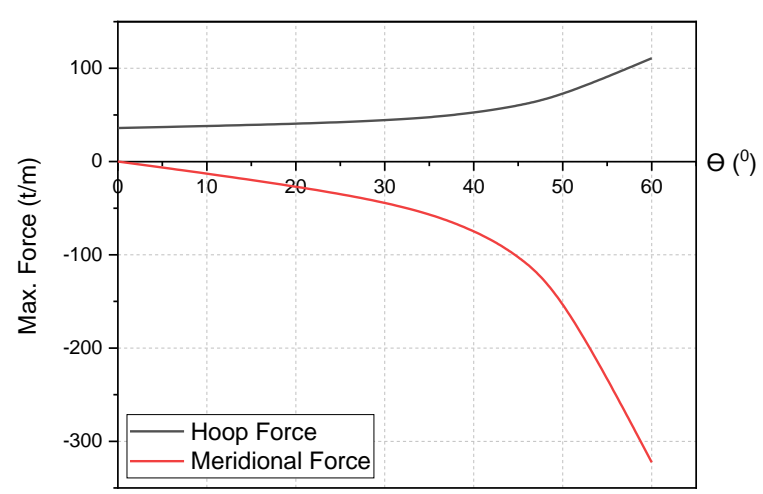

Figure 5. Maximum internal actions in tanks with different inclination angles. $(\mathrm{r}=4 \mathrm{~m}$ and Htank $=9 \mathrm{~m})$ hoop forces occur decreases gradually from $1 / 3$ to $1 / 6$ of the tank height. On the other hand, the meridional forces decrease with the increase of the tank bottom radius. This is attributed to the increase of the resisting perimeter in wider tanks.

\section{Effect of Tank Height}

Figs. 8 and 9 show the results of analysis of conical tanks having bottom radius of $4 \mathrm{~m}$ and an inclination angle of $45^{\circ}$ with various heights of $7,8,9$, and $10 \mathrm{~m}$. Clearly, both the maximum hoop and meridional forces linearly increase by increasing the tank height. The maximum hoop force occurs at $0.21,0.24,0.27$, and 0.30 of the tank height for tanks with 7 , 8,9 , and $10 \mathrm{~m}$ height, respectively. It is also observed that, the meridional forces increase at a higher rate than the hoop forces.

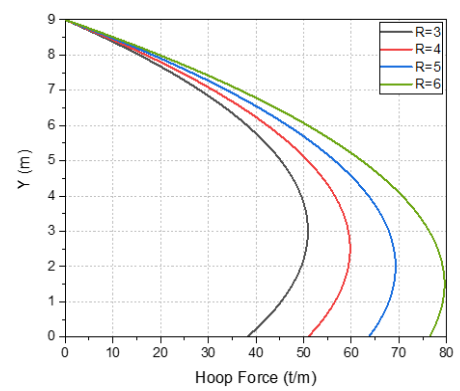

(a)

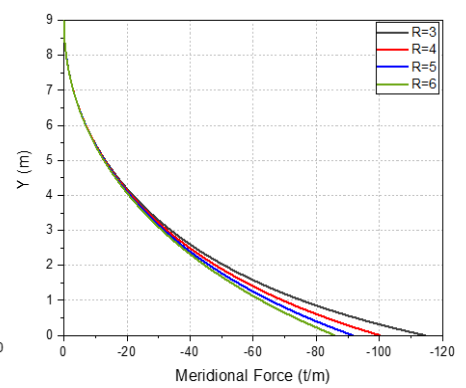

(b)
Figure 6. Distribution of internal actions for different footprint radii. $\left(\Theta=45^{\circ}\right.$ and $\left.\mathrm{H}_{\text {tank }}=9 \mathrm{~m}\right)$

(a) Hoop forces, and (b) Meridional forces.

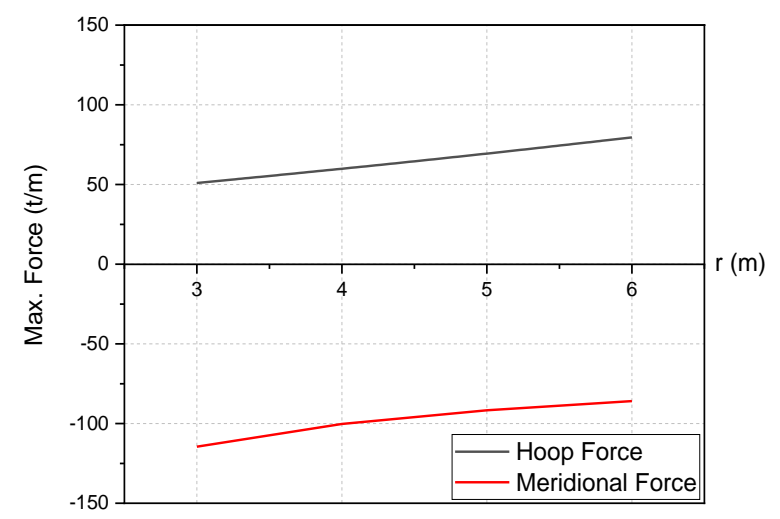

Figure 7. Maximum internal actions in tanks with different footprint radii. $\left(\Theta=45^{\circ}\right.$ and $\left.\mathrm{Htank}=9 \mathrm{~m}\right)$

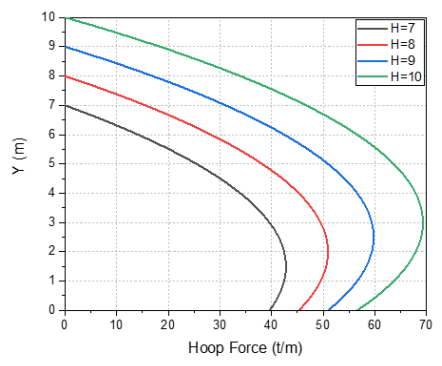

(a)

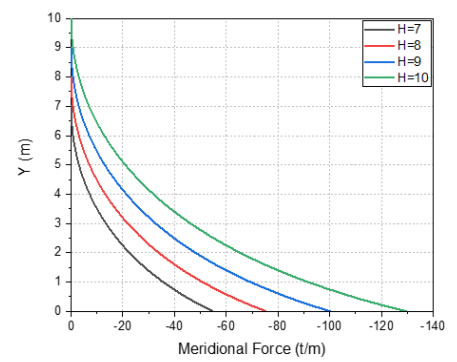

(b)
Figure 8. Distribution of internal actions for different tank heights. $\left(\Theta=45^{\circ}\right.$ and $\left.\mathrm{r}=4 \mathrm{~m}\right)$

(a) Hoop forces, and (b) Meridional forces. 


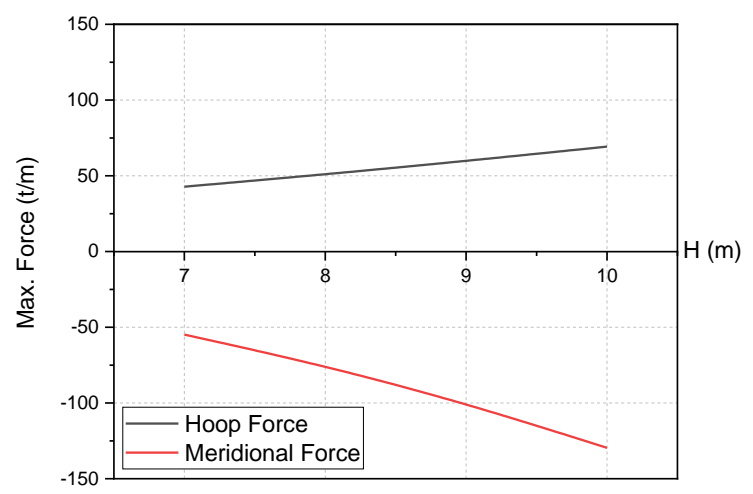

Figure 9. Maximum internal actions in tanks with different tank heights. $\left(\Theta=45^{\circ}\right.$ and $\left.r=4 m\right)$

\section{Guide for Preliminary Dimensioning}

To get an insight into the optimum preliminary dimensioning of a tank in terms of its volume capacity, sample design charts for tanks with $4 \mathrm{~m}$ footprint radius, are presented in Fig. 10. It shows the maximum internal forces in tanks having different heights and inclination angles. For example, given the footprint radius, one can use these charts to obtain the suitable height for the required volume. Knowing these parameters (footprint radius and tank height), the inclination angle satisfying the desired tank capacity can be easily calculated. Other charts can be generated for different footprint radii.

It should be emphasized that this simple guide is limited to the early stage of tank dimensioning, but the detailed design should rely on a more accurate analysis tool such as finite element method (FEM) or equations and charts developed using FEM such as [22,23].

\section{CONCLUSIONS}

Based on the results of the current study the following conclusions can be drawn:

1- The hoop forces were observed to increase when increasing any of the dimension parameters (inclination angle, footprint radius, and height) of the tank.

2- The meridional forces were observed to increase when increasing the tank inclination angle or height, but they decrease when increasing the footprint radius.

3- The maximum meridional forces occur at the bottom rim of the vessel.

4- The maximum hoop forces take place at the lower one third of the tank height and its location varies depending on the tank geometry.

5- The presented analysis, though being simple, can give the designer an insight about the effect of various parameters on the internal forces acting on this type of tanks under hydrostatic loading.

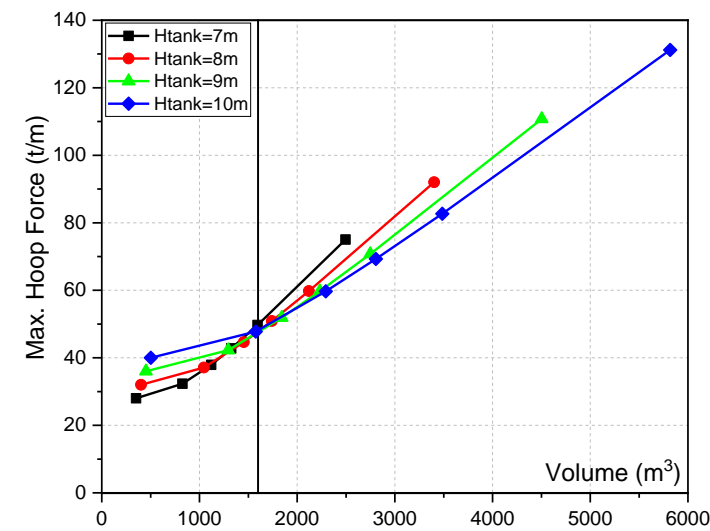

(a)

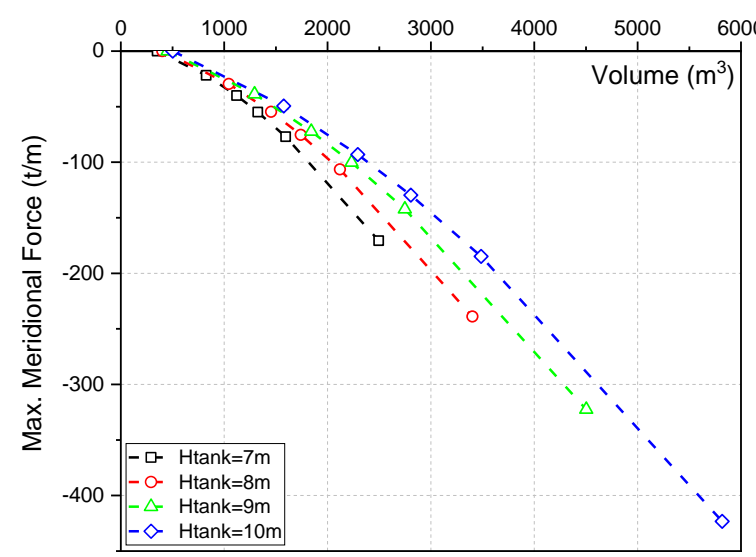

(b)

Figure 10. Maximum internal actions in tanks with different tank heights and inclination angles $(\mathrm{r}=4 \mathrm{~m})$

(a) Hoop forces, and (b) Meridional forces

\section{REFERENCES}

[1] Vandepitte D. Model investigation of the collapse of a steel water tower Prelim. Rep. 2nd Int. Colloq. Stab. shell Struct., Liege: 1977, p. 599607.

[2] Korol W. An Assessment of Fredericton's Regent Steel Tower Reservoir Failure Technical report. Hamilton (Canada): 1991.

[3] Vandepitte D, Rathe J, Verhegghe B, Paridaens R, Verschaeve C. Experimental investigation of buckling of hydrostatically loaded, conical shells and practical evaluation of the buckling load. Buckl Shell Berlin Heidelb Springer 1982:375-99.

[4] El Damatty AA, Korol RM, Mirza FA. Stability of imperfect steel conical tanks under hydrostatic loading. J Struct Eng 1997;123:703-12. https://doi.org/10.1061/(asce)0733-9445(1998)124:10(1231).

[5] Koziey BL, Mirza FA. Consistent thick shell element. Comput Struct 1997;65:531-49. https://doi.org/10.1016/S0045-7949(96)00414-2.

[6] El Damatty AA, Korol RM, Mirza FA. Large displacement extension of consistent shell element for static and dynamic analysis. Comput Struct 1997;62:943-60.

[7] Discussion by Vandepitte D. Closure by El Damatty AA. On El Damatty AA, Korol RM, Mirza FA. Stability of imperfect steel conical tanks under hydrostatic loading. Discussion by Vandepitte D. Closure by El Damatty AA. J Struct Eng 1998:1231-2.

[8] El Damatty AA, El-Attar M, Korol RM. Inelastic stability of conical tanks. Thin-Walled $\quad$ Struct 1998;31:343-59. https://doi.org/10.1016/S0263-8231(98)00020-2.

[9] Lagae GAME, Vanlaere WMH, Impe RE Van. Plastic buckling of conical tanks with large geometrical imperfections. Rene Maquoi 65th Birthd. Anniv., Liège, Belgium: 2007. 
[10] Tekleab MB. Buckling of thin-walled cylindrical \& conical metal tanks: analysis, test evaluation \& design. Graz University of Technology, 2009.

[11] Azabi TM, El Ansary AM, El Damatty AA. Analysis and design of elevated liquid-filled reinforced concrete conical tanks. Adv Struct Eng 2016;19:995-1008. https://doi.org/10.1177/1369433216630824.

[12] PCA-CCTWP. Circular concrete tanks without pre-stressing. Skokie, IL: Portland Cement Association (PCA). 1993.

[13] American Water Works Association (AWWA). Welded carbon steel tanks for water storage, AWWA D-100. Denver, Colo. 2005.

[14] Elansary AA, El Damatty AA, El Ansary AM. Nonlinear behaviour of reinforced concrete conical tanks under hydrostatic pressure. Can J Civ Eng 2015;43:85-98. https://doi.org/10.1139/cjce-2015-0198.

[15] Elansary AA, El Damatty AA. Behavior of elevated liquid-filled concrete conical tanks. Proceedings, Annu. Conf. - Can. Soc. Civ. Eng., vol. 4, 2013, p. 2987-96.

[16] Pietruszczak S, Jiang J, Mirza FA. An elastoplastic constitutive model for concrete. Int J Solids Struct 1988;24:705-22. https://doi.org/10.1016/0020-7683(88)90018-2.

[17] Jaing J. Modeling of mechanical behavior of concrete structures. Hamilton (ON, Canada): McMaster University, 1988.

[18] Bruder M. Cylindrical concrete tanks with a conical base - Internal force discrepancies between different analysis tools. 2nd Int. Eng. Mech. Mater. Spec. Conf., Ottawa, Ontario: 2011.

[19] Elansary AA, El Damatty AA. Behaviour of composite conical tanks under hydrostatic pressure. Eng Struct 2017;134:172-89. https://doi.org/10.1016/j.engstruct.2016.12.041.

[20] Siddique MAA, El Damatty AA. Enhancement of buckling capacity of steel plates strengthened with GFRP plates. Thin-Walled Struct 2012;60:154-62. https://doi.org/10.1016/j.tws.2012.06.013.

[21] Bakhoum M. Structural Mechanics - Volume II. 1992.

[22] El Damatty AA, El-Attar M, Korol RM. Simple design procedure for liquid-filled steel conical tanks. J Struct Eng 1999;125:879-90.

[23] Sweedan AMI, El Damatty AA. Simplified procedure for design of liquid-storage combined conical tanks. Thin-Walled Struct 2009;47:750-9. https://doi.org/10.1016/j.tws.2008.12.005. 